\title{
Produksi dan Kualitas Buah Stroberi pada Beberapa Sistem Irigasi
}

\author{
The Fruit Production and Quality of Strawberry Under Several Irrigation System
}

\author{
Slamet Susanto ${ }^{\mathrm{i}^{*}}$, Bhayu Hartanti ${ }^{2}$ dan Nurul Khumaida ${ }^{1}$ \\ Diterima 21 Oktober 2009/Disetujui 24 Februari 2010
}

\begin{abstract}
The objectives of this research was to study the fruit production and quality of strawberry grown under different irrigation system. The trial was arranged in a completely randomized design. Four irrigation systems were examined: drip irrigation applied daily, drip irrigation applied every 2 days, manual irrigation applied daily and manual irrigation applied every 2 days. The result showed that the treatments gave significant effects on vegetative growth. Plants irrigated daily produced more runner than those iritgated every 2 days. Plants irrigated mamually every 2 days lowered flower production. The drip irrigation applied daily gave the highest response on growth and yield without any difference on fruit quality. The system could be considered for hydroponic strawberry production.
\end{abstract}

Key words: strawberry, irrigation, fruit production, fruit quality

\section{PENDAHULUAN}

Stroberi (Fragaria $x$ ananassa. Duch.) merupakan salah satu tanaman buah anggota famili Rosaceae yang populer di banyak negara, baik negara temperate maupun negara tropis seperti Indonesia. Di Amerika Serikat, pada musim semi buah ini termasuk buah utama yang mendominasi pasar (Childers, 1973). Buah stroberi biasa dikonsumsi dalam keadaan segar ataupun produk olahannya seperti sirup, sari buah, selai dan untuk campuran es krim. Buah stroberi mengandung nutrisi yang cukup tinggi terutama kalsium, vitamin $\mathrm{C}$ dan karbohidrat (Shamaila et al., 1992).

Buah stroberi mempunyai nilai ekonomis yang tinggi, disertai dengan permintaan yang terus meningkat, sehingga budidaya tanaman stroberi mempunyai prospek yang baik untuk dikembangkan di Indonesia. Namun demikian, keadaan iklim yang ada di Indonesia kurang mendukung untuk budidaya tanaman stroberi. Tanaman stroberi merupakan tanaman subtropis yang telah lama diintroduksi dan dapat beradaptasi di dataran tinggi tropis. Menurut Choopong dan Veirheij (1997) budidaya tanaman stroberi di daerah tropis dapat berhasil jika dilakukan di daerah dataran tinggi yang mempunyai elevasi diatas $1000 \mathrm{~m}$ di atas permukaan laut (dpl) dengan suhu $17-20{ }^{\circ} \mathrm{C}$. Oleh karena itu, di Indonesia budidaya tanaman stroberi banyak diusahakan di dataran tinggi seperti Lembang, Ciwidey, Cianjur, Sukabumi dan Brastagi.

Faktor yang sangat penting dalam budidaya stroberi adalah suhu, panjang hari dan suplai air.
Tanaman stroberi dapat tumbuh baik pada suhu 17 $20{ }^{\circ} \mathrm{C}$, dengan lama penyinaran 8-10 jam dengan suplai air dan hara yang cukup (Gunawan, 1996; Edmond et al., 1957). Untuk mengoptimalkan kondisi lingkungan, salah satu usaha yang dapat dilakukan adalah dengan membudidayakan stroberi dengan sistem hidroponik (Noviyanti dan Susanto, 2005). Schwarz (1995) menyatakan bahwa budidaya secara hidroponik mempunyai banyak keuntungan, diantaranya tidak membutuhkan lahan yang luas, kebutuhan air, hara dan cahaya mudah diatur sesuai dengan kebutuhan tanaman, pengendalian hama dan penyakit lebih mudah, serta lebih steril karena tidak menggunakan tanah.

Budidaya secara hidroponik dapat berhasil apabila kebutuhan air, sirkulasi udara dan hara tanaman tercukupi. Dalam budidaya tanaman secara hidroponik media tanam yang digunakan bersifat inert, sehingga untuk memenuhi kebutuhan hara tanaman, tanaman harus disiram dan mendapatkan suplai hara dari luar. Hal ini meyebabkan biaya yang dibutuhkan tinggi dan tenaga kerja yang dibutuhkan banyak. Untuk meminimalkan biaya, penyiraman dan pemupukan dapat dilaksanakan bersamaan dengan menggunakan irigasi tetes. Hansen et al. (1980) menyatakan bahwa efisiensi pemakaian air pada irigasi tetes mendekati $100 \%$. Walaupun biaya investasi awal dalam pembuatan irigasi tetes mahal, namun dalam pengoperasiannya hemat tenaga kerja, air dan hara. Penelitian ini diharapkan dapat memberikan informasi tentang sistem irigasi yang efektif dan efisien untuk budidaya tanaman stroberi secara hidroponik.

\footnotetext{
${ }^{1}$ Staf Pengajar Departemen Agronomi dan Hortikultura, Fakultas Pertanian, IPB

J. Meranti Kampus IPB Darmaga, Bogor 16680 Telp/Fax (0251) 8629353 Email: ssanto@cbn.net.id

( ${ }^{*}$ Penulis untuk korespondensi)

${ }^{2}$ Alumni Departemen Agronomi dan Hortikultura
} 
Penelitian ini bertujuan untuk :

1. Mempelajari pengaruh sistem irigasi terhadap pertumbuhan tanaman dan kualitas buah stroberi yang ditanam secara hidroponik

2. Mengetahui sistem irigasi yang paling sesuai untuk tanaman stroberi yang ditanam secara hidroponik.

\section{BAHAN DAN METODE}

Penelitian dilaksakan di kebun petani stroberi Desa Segunung, Kecamatan Pacet, Cipanas yang mempunyai elevasi $900 \mathrm{~m}$ dpl. Analisis kualitas buah dilaksanakan di laboratorium Pusat Kajian Buah-buahan Tropika (PKBT) Institut Pertanian Bogor. Penelitian dilaksanakan mulai bulan Oktober 2005 sampai bulan Februari 2006.

Bahan tanaman yang digunakan dalam penelitian ini adalah bibit stroberi aksesi nomor 12 sebanyak 80 bibit. Penelitian ini menggunakan Rancangan Acak Lengkap satu faktor, yaitu sistem irigasi yang terdiri dari empat taraf, yaitu : Irigasi drip setiap hari (P1), Irigasi drip dua hari sekali (P2), Irigasi manual setiap hari (P3), dan Irigasi manual dua hari sekali (P4). Setiap perlakuan diulang 10 kali. Satu satuan percobaan terdiri atas 2 tanaman, sehingga total bibit yang dibutuhkan sebanyak 80 bibit. Dalam satu kali aplikasi penyiraman, larutan hara yang diberikan sebanyak 0.5 liter untuk setiap polibag.

Bibit yang digunakan berasal dari runner yang sehat dan mempunyai ukuran yang seragam. Bibit yang berumur 3 minggu, ditanam dalam polibag

Tabel 1. Klasifikasi dan standar mutu buah stroberi yang telah diisi media arang sekam, satu polibag dua tanaman. Setelah ditanam, polibag yang berisi tanaman stroberi diletakkan di atas bedengan dengan jarak antar polibag $40 \mathrm{~cm}$, kemudian tanaman disiram dengan larutan hara secara manual sebanyak 0.5 liter/polibag dengan frekuensi dua hari sekali.

Setelah tanaman berumur dua bulan, tanaman diwiwil daunnya dan dilakukan pembuangan bunga serta buah untuk menyeragamkan kondisi tanaman, kemudian tanaman stroberi mulai diirigasi sesuai dengan perlakuan. Selain penyiraman, pemeliharaan yang dilakukan adalah pewiwilan daun yang tua dan rusak setiap 4 minggu sekali dan pengendalian hama dan penyakit. Pengamatan meliputi peubah vegetatif dan generatif tanaman serta kualitas buah. Panen mulai dilakukan setelah tanaman berumur \pm 8 minggu setelah perlakuan (MSP).

Peubah yang diamati meliputi: tinggi tanaman, jumlah daun, jumlah runner, waktu mulai berbunga, waktu mulai panen, waktu akhir panen, jumlah bunga, persentase bunga gugur, jumlah dan bobot buah, kekerasan buah, kandungan padata terlarut total (PTT) dan asam buah serta pengkelasan buah. Pengamatan peubah kekerasan buah, padatan terlarut total, total asam tertitrasi dan ukuran buah dilakukan pada saat panen.

Kekerasan buah diukur dengan hand penetrometer pada tiga bagian, yaitu ujung, tengah dan pangkal buah kemudian dirata-ratakan. PTT diukur dengan refractometer. Kandungan total asam diukur dengan metode titrasi menggunakan $\mathrm{NaOH}$. Pengkelasan buah dilakukan berdasarkan bobot buah dan kemulusan penampilannya (Tabel 1).

\begin{tabular}{lll}
\hline Kelas & Bobot/buah $(\mathrm{g})$ & \\
\hline Super & $>20$ & Mulus, tidak cacat \\
A & $12-20$ & Mulus, tidak cacat \\
B & $7-11$ & Mulus, tidak cacat \\
C* & $4-7$ & Termasuk buah besar yang cacat, salah bentuk, sedikit busuk dan buah muda \\
Afkir* & $<4$ & Semua buah yang mempunyai bobot $<4 \mathrm{~g}$ \\
\hline
\end{tabular}

Sumber: Warintek (2004), * dimodifikasi dari hasil pengamatan visual penulis

\section{HASIL DAN PEMBAHASAN}

Secara umum tanaman yang mendapat irigasi setiap hari, baik secara manual ataupun menggunakan irigasi drip memperlihatkan pertumbuhan vegetatif yang lebih baik dibandingkan tanaman yang mendapat irigasi dua hari sekali. Secara visual, tanaman yang diirigasi setiap hari tampak lebih besar dengan daun yang lebar dan tangkai daun yang besar dan lebih kokoh. Tanaman yang diirigasi dua hari sekali mempunyai daun yang lebih sempit dan tangkai daun yang kurus (Gambar 1). Pada akhir pengamatan tanaman yang mendapat perlakuan irigasi setiap hari nyata lebih tinggi dibandingkan tanaman yang mendapat irigasi dua hari sekali, baik menggunakan irigasi drip maupun secara manual (Tabel 2). 


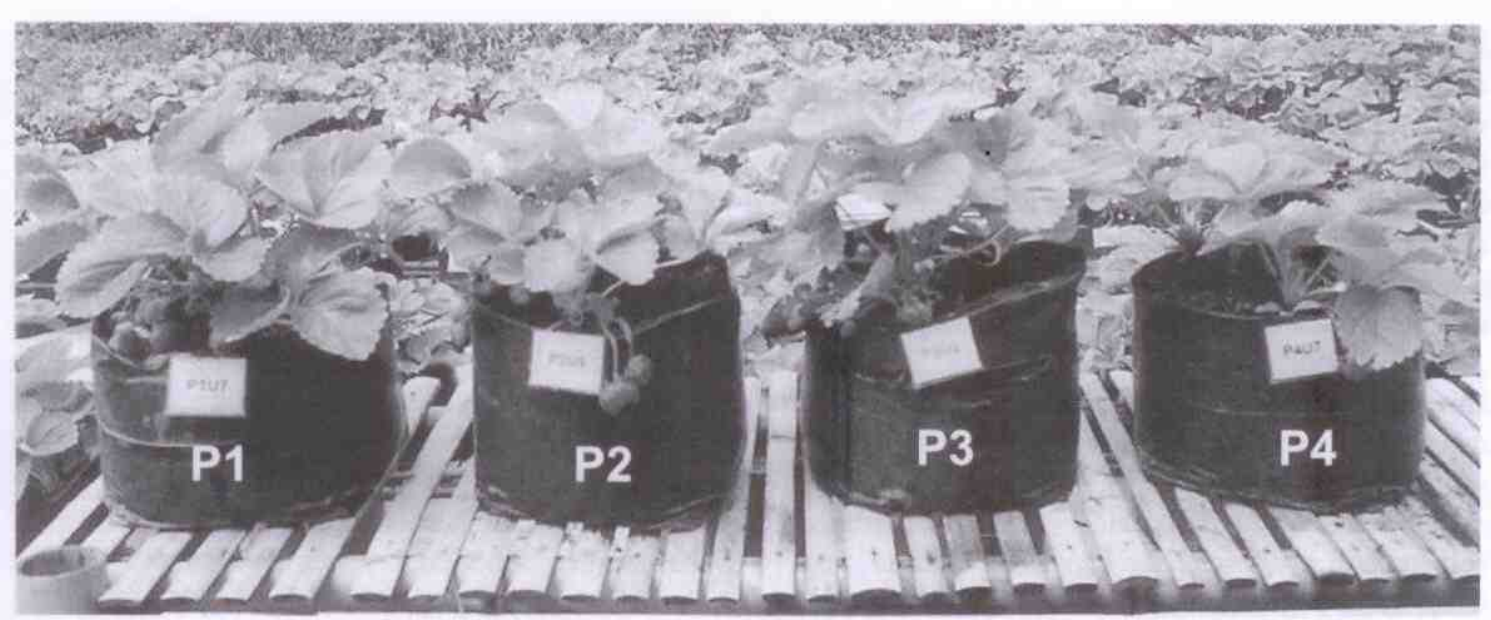

Gambar 1. Penampilan tanaman stroberi pada empat perlakuan irigasi saat 9 MSP
Keterangan :
P1 : Irigasi drip setiap hari
P2 : Irigasi drip dua hari sekali
$\mathrm{P} 3$ : Irigasi manual setiap hari
P4 : Irigasi manual dua hari sekali

Tabel 2. Tinggi tanaman, jumlah daun dan jumlah runner stroberi pada empat perlakuan irigasi pada $12 \mathrm{MSP}$

\begin{tabular}{lccc}
\hline Perlakuan & Tinggi tanaman $(\mathrm{cm})$ & Jumlah daun & Jumlah runner \\
\hline Drip setiap hari & $26.8 \mathrm{a}$ & 19.4 & $3.8 \mathrm{a}$ \\
Drip dua hari sekali & $24.8 \mathrm{~b}$ & 19.5 & $2.1 \mathrm{~b}$ \\
Manual setiap hari & $27.0 \mathrm{a}$ & 17.8 & $3.4 \mathrm{a}$ \\
Manual dua hari sekali & $24.7 \mathrm{~b}$ & 18.0 & $2.2 \mathrm{~b}$ \\
\hline
\end{tabular}

Keterangan : - Angka-angka yang diikuti oleh huruf yang sama pada kolom yang sama adalah tidak berbeda nyata pada uji DMRT taraf $5 \%$

\section{Jumlah Daun}

Jumlah daun mulai dihitung sesaat sebelum perlakuan. Sebelum memulai perlakuan, daun tanaman diwiwil dan disisakan 3 sampai 4 helai daun. Dari Tabel 2 dan Gambar 2 menunjukkan jumlah daun per tanaman tidak menunjukkan perbedaan yang nyata. Pada akhir pengamatan, jumlah daun berkisar antara 17 sampai 20 helai.

\section{Jumlah Runner}

Runner mulai dihitung mulai 2 MSP setelah tanaman menghasilkan runmer. Rata-rata jumlah nunner yang dihasilkan pada setiap pengamatan tidak menunjukkan perbedaan yang nyata, kecuali pada 10 MSP. Namun demikian total numner yang dihasilkan selama 12 minggu pengamatan menunjukkan perbedaan yang nyata (Tabel 2). Tanaman yang mendapat irigasi setiap hari, baik dengan menggunakan drip ataupun manual menghasilkan runner yang lebih banyak dibandingkan tanaman yang mendapat irigasi dua hari sekali. Produksi nummer mengalami peningkatan saat tanaman berumur 2 MSP ke 4 MSP, kemudian terus menurun pada 6 MSP dan 8 MSP dan mulai meningkat lagi pada saat 10 MSP (Gambar 3).

\section{Waktu Mulai Berbunga, Mulai Panen dan Akhir Panen pada Dua Periode Panen}

Pada periode panen pertama, saat mulai berbunga, saat mulai panen dan saat akhir panen tidak menunjukkan perbedaan yang nyata antar perlakuan. Pada semua perlakuan, tanaman stroberi mulai berbunga saat 4 MSP dan mulai panen saat tanaman berumur 7-8 MSP. Panen periode pertama berakhir pada 9-10 MSP. 
Pada periode panen kedua, perbedaan sistem irigasi menunjukkan pengaruh yang sangat nyata terhadap saat munculnya bunga. Tanaman stroberi yang mendapat perlakuan irigasi setiap hari relatif lebih cepat berbunga dibandingkan tanaman stroberi yang mendapatkan irigasi dua hari sekali. Pada periode panen kedua, bunga mulai muncul pada saat tanaman berumur 11 sampai 12 MSP (Tabel 3 ).

\section{Jumlah Bunga dan Persentase Bunga Gugur selama Dua Periode Panen}

Perbedaan perlakuan sistem irigasi berpengaruh nyata terhadap banyaknya bunga yang dihasilkan. Jumlah bunga yang dihasilkan oleh tanaman yang mendapat irigasi manual dua hari sekali nyata lebih sedikit dibandingkan perlakuan yang lain, yaitu sebanyak 37.3 bunga per tanaman.

Persentase bunga yang gugur selama dua periode panen tidak menunjukkan perbedaan yang nyata. Dari dua periode panen, persentase bunga gugur tergolong tinggi yaitu berkisar $60 \%$ sampai $66 \%$ (Tabel 4).

\section{Rata-rata Bobot per Buah, Jumlah Buah dan Bobot Buah Panen}

Rata-rata bobot per buah, jumlah buah panen per tanaman dan bobot buah panen per tanaman selama dua periode panen tidak memperlihatkan perbedaan yang nyata. Namun demikian, produktivitas dan bobot buah tanaman stroberi yang mendapatkan irigasi setiap hari cenderung lebih tinggi dibandingkan dengan perlakuan lainnya. Jumlah dan bobot buah panen terbesar dicapai oleh tanaman dengan perlakuan irigasi drip setiap hari yaitu 6.9 buah per tanamań dengan bobot buah panen $85.11 \mathrm{~g}$ per tanaman. Jumlah dan bobot buah panen terkecil terjadi pada tanaman stroberi dengan perlakuan irigasi manual setiap hari, yaitu 5.9 buah per tanaman dengan bobot buah panen $61.8 \mathrm{~g}$ per tanaman. Rata-rata bobot buah stroberi berkisar antara 10 sampai $13 \mathrm{~g}$ (Tabel 5).

Tabel 3. Waktu mulai berbunga, mulai panen dan akhir panen tanaman stroberi pada dua periode panen

\begin{tabular}{lcccccc}
\hline \multirow{2}{*}{ Perlakuan } & \multicolumn{2}{c}{ Periode panen pertama (MSP) } & \multicolumn{2}{c}{ Periode panen kedua (MSP) } \\
\cline { 2 - 6 } & $\begin{array}{c}\text { Mulai } \\
\text { berbunga }\end{array}$ & $\begin{array}{c}\text { Mulai } \\
\text { panen }\end{array}$ & $\begin{array}{c}\text { Akhir } \\
\text { panen }\end{array}$ & $\begin{array}{c}\text { Mulai } \\
\text { berbunga }\end{array}$ & $\begin{array}{c}\text { Mulai } \\
\text { panen }\end{array}$ & $\begin{array}{c}\text { Akhir } \\
\text { panen }\end{array}$ \\
\hline Drip setiap hari & 4.0 & 7.5 & 9.8 & $11.4 \mathrm{~b}$ & 14.9 & 17.1 \\
Drip dua hari sekali & 4.0 & 7.3 & 10.1 & $12.0 \mathrm{a}$ & 15.2 & 17.2 \\
Manual setiap hari & 4.0 & 7.7 & 9.8 & $11.3 \mathrm{~b}$ & 14.9 & 17.2 \\
Manual dua hari sekali & 3.8 & 7.2 & 9.9 & $11.7 \mathrm{ab}$ & 15.2 & 17.5 \\
\hline
\end{tabular}

Keterangan : - Angka-angka yang diikuti oleh huruf yang sama pada kolom yang sama adalah tidak berbeda nyata pada uji DMRT taraf $5 \%$

- MSP = Minggu Setelah Perlakuan

Tabel 4. Rata-rata jumlah bunga per tanaman dan persentase bunga gugur pada tanaman stroberi selama dua periode panen

\begin{tabular}{lcc}
\hline Perlakuan & Jumlah bunga & \% Bunga gugur \\
\hline Drip setiap hari & $43.4 \mathrm{a}$ & 65.8 \\
Drip dua hari sekali & $42.3 \mathrm{a}$ & 61.6 \\
Manual setiap hari & $42.0 \mathrm{a}$ & 61.2 \\
Manual dua hari sekali & $37.3 \mathrm{~b}$ & 60.2 \\
\hline
\end{tabular}

Keterangan : - Angka-angka yang diikuti oleh huruf yang sama pada kolom yang sama adalah tidak berbeda nyata pada uji DMRT taraf 5\%

\section{Ukuran Buah}

Pengkelasan buah stroberi didasarkan atas bobot buah, seperti yang terlihat pada Tabel 1 . Gambar 4 menunjukkan bahwa untuk buah yang layak jual, persentase bobot buah tertinggi adalah buah kelas A diikuti oleh buah kelas $\mathrm{C}$, kelas $\mathrm{B}$ dan kelas Super.

Pada perlakuan irigasi drip setiap hari persentase bobot buah kelas super lebih tinggi 
Tabel 5. Rata-rata bobot per buah, jumlah buah panen dan bobot buah panen per tanaman stroberi selama dua periode panen.

\begin{tabular}{lccc}
\hline Perlakuan & Bobot per buah $(\mathrm{g})$ & Jumlah buah $/$ tanaman & Bobot buah $\operatorname{tanaman}(\mathrm{g})$ \\
\hline Drip setiap hari & 13.09 & 6.9 & 85.11 \\
Drip dua hari sekali & 10.67 & 6.0 & 64.13 \\
Manual setiap hari & 11.32 & 6.2 & 70.09 \\
Manual dua hari sekali & 10.29 & 5.9 & 61.75 \\
\hline
\end{tabular}

Tabel 6. Rata-rata kekerasan, padatan terlarut total dan asam tertitrasi total buah stroberi

\begin{tabular}{lccc}
\hline Perlakuan & Kekerasan $\left(\mathrm{mm} \mathrm{kg}^{-1}\right)$ & Padatan terlarut total ( brix) & Asam tertitrasi total (\%) \\
\hline Drip setiap hari & 0.66 & 6.33 & 2.42 \\
Drip dua hari sekali & 0.71 & 7.00 & 2.21 \\
Manual setiap hari & 0.71 & 6.80 & 2.50 \\
Manual dua hari sekali & 0.68 & 6.90 & 2.29 \\
\hline
\end{tabular}

dibandingkan buah kelas $\mathrm{B}$, yaitu lebih dari $15 \%$. Persentase buah super pada perlakuan irigasi drip setiap hari adalah yang paling tinggi dibandingkan dengan perlakuan yang lain. Buah kelas A mempunyai persentase sebesar $23-27 \%$. Buah yang masuk kelas afkir mempunyai persentase terkecil, yaitu berkisar antara $2-5 \%$ dari total bobot buah. Persentase buah busuk untuk semua perlakuan tergolong tinggi, berkisar antara 20-27\% (Gambar 4).

\section{Kekerasan, Padatan Terlarut Total (PTT) dan Asam Tertitrasi Total (ATT) Buah}

Secara statistik, perlakuan irigasi tidak berpengaruh nyata terhadap kekerasan buah, padatan terlarut total dan total asam tertitrasi. Nilai kekerasan buah stroberi berkisar antara $0.66 \mathrm{~mm} \mathrm{~kg}^{-1}$ sampai $0.71 \mathrm{~mm} \mathrm{~kg}^{-1}$. Nilai kekerasan buah menunjukkan berapa dalam jarum penetrometer dapat masuk dalam daging buah stroberi. Semakin tinggi nilai kekerasannya, buah semakin lunak. Nilai PTT berkisar antara $6.33^{\circ}$ brix sampai $7.00^{\circ}$ brix dan ATT buah stroberi berkisar $2.21 \%$ sampai $2.50 \%$ (Tabel 6).

\section{PEMBAHASAN}

Terdapat dua fase pertumbuhan tanaman, yaitu pertumbuhan vegetatif dan reproduktif. Fase vegetatif tanaman terutama terjadi pada perkembangan akar, daun dan batang. Namun demikian, untuk tanaman stroberi, fase vegetatif juga ditandai dengan munculnya anakan dan tumbuhnya runner. Pertumbuhan reproduktif tanaman ditandai dengan pembentukan bunga, buah dan biji.

Menurut Robert et al. (1999) panjang petiol daun adalah variabel terbaik untuk mengevaluasi pertumbuhan tanaman stroberi. Pada penelitian ini, tinggi tanaman stroberi diukur mulai dari pangkal petiol sampai ujung daun tertinggi. Perbedaan perlakuan irigasi berpengaruh nyata terhadap jumlah total runner yang dihasilkan dan tinggi tanaman. Tanaman yang mendapat irigasi setiap hari baik menggunakan drip maupun secara manual mempunyai tajuk yang lebih tinggi dibandingkan tanaman yang mendapat irigasi setiap dua hari sekali. Prawiranata et al. (1995) menyatakan bahwa air berperan penting dalam pemanjangan sel selama proses pertumbuhan. Peningkatan frekuensi irigasi akan meningkatkan jumlah air yang dapat terserap oleh tanaman, sehingga dapat mendorong pemanjangan sel yang akhirnya dapat meningkatkan tinggi tajuk tanaman.

Jumlah runner yang dihasilkan menunjukkan perbedaan yang nyata antara tanaman yang mendapat irigasi setiap hari dan tanaman yang mendapatkan irigasi dua hari sekali. Tanaman yang mendapatkan irigasi setiap hari, selama 12 minggu pengamatan menghasilkan rumner yang lebih banyak dibandingkan tanaman yang mendapat irigasi dua hari sekali. Save et al. (1993) menyatakan bahwa pemberian irigasi pada stroberi dapat meningkatkan pertumbuhan stroberi dan meningkatkan produksi runner. 


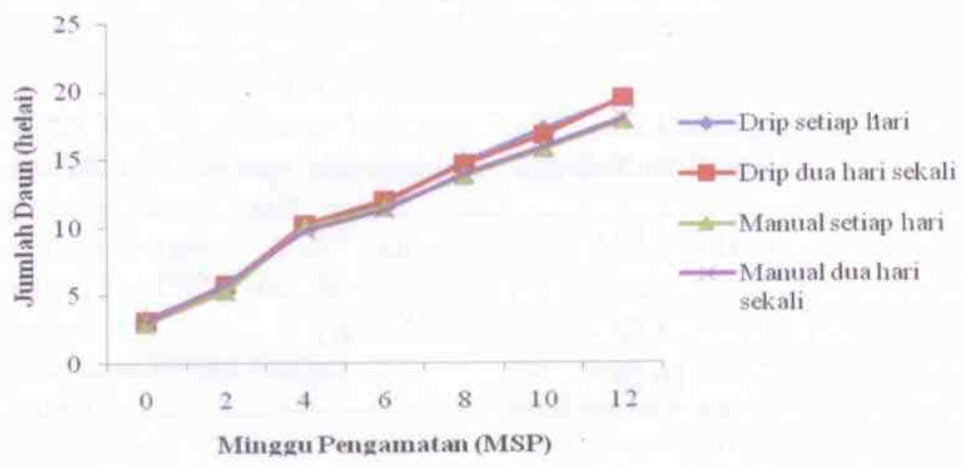

Gambar 2. Perkembangan jumlah daun stroberi pada empat perlakuan irigasi

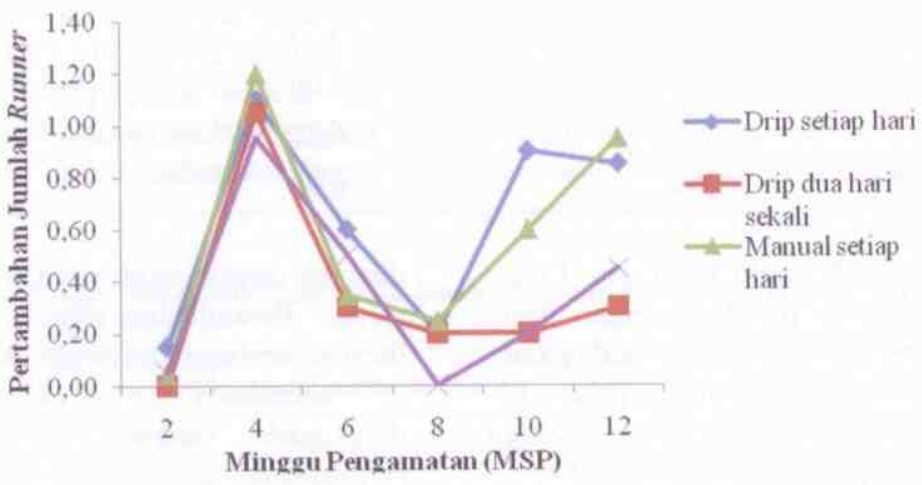

Gambar 3. Pertambahan jumlah runner pada empat perlakuan irigasi

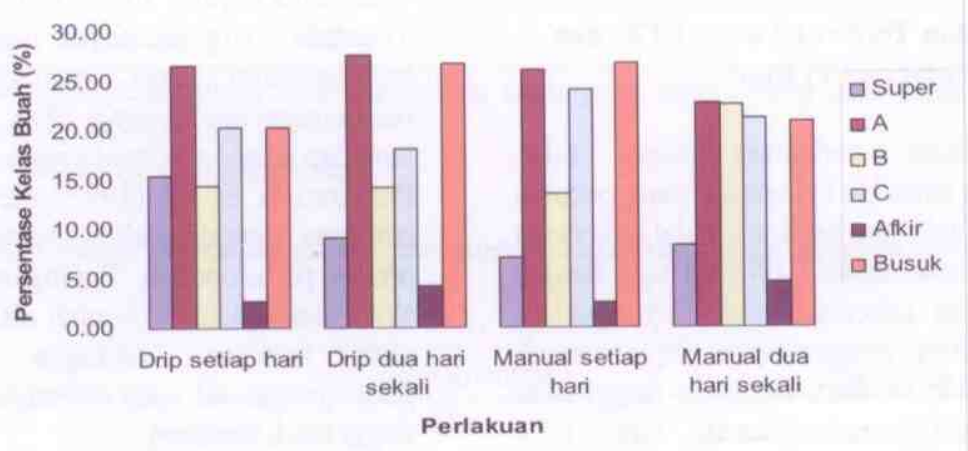

Gambar 4. Pengkelasan buah stroberi pada empat perlakuan irigasi

Produksi rumner mengalami peningkatan dari 2 MSP ke 4 MSP kemudian mengalami penurunan pada 6 MSP dan 8 MSP. Pada 6 MSP runner yang dihasilkan mengalami penurunan karena pada minggu keempat tanaman mulai menghasilkan bunga dan memasuki fase generatif. Menurut Schneider dan Scarbourough (1960), tanaman stroberi yang berada pada masa pembungaan akan memusatkan fotosintat pada bunga dan buah sehingga pertumbuhan vegetatif tanaman terhambat. Pada 10 MSP, tanaman yang mendapatkan irigasi setiap hari menghasilkan jumlah runner yang lebih banyak karena pada awal minggu ke-10 masa reproduktif tanaman sudah berakhir dan kembali ke fase vegetatif sehingga fotosintat terkonsentrasi kembali untuk pertumbuhan vegetatif. Pada waktu yang sama tanaman yang mendapatkan irigasi dua hari sekali masih berada pada fase generatif. Puncak 
produksi runner terjadi pada saat tanaman berada pada fase vegetatif yaitu pada umur 2 sampai 4 MSP dan 10 sampai 12 MSP. Periode ini dapat dimanfaatkan untuk memperbanyak runner sebagai bibit. Banyaknya rumner yang diproduksi tanaman stroberi mempunyai peranan penting dalam perbanyakan bibit.

Pada periode panen pertama tidak terjadi perbedaan waktu munculnya bunga. Pada semua perlakuan, rata-rata tanaman mulai berbunga pada 4 MSP dan buah mulai dapat dipanen sekitar 7 MSP. Pada panen pertama, panen dapat dilakukan sampaí tiga minggu. Setelah buah habis, tanaman kembali memasuki fase vegetatif kembali selama dua minggu dan mulai menghasilkan bunga kembali pada akhir minggu kesebelas. Pada periode panen kedua, tanaman dengan perlakuan irigasi setiap hari cenderung berbunga lebih cepat. Hal ini diduga karena kebutuhan air dan nutrisi tanaman pada perlakuan irigasi setiap dua hari sekali kurang mencukupi kebutuhan tanaman.

Dari hasil penelitian ini dapat diketahui bahwa tanaman stroberi dapat berbunga sepanjang tahun. Hal ini sesuai dengan pernyataan Choopong dan Verheij (1997), bahwa di daerah tropik tanaman stroberi mampu berbunga sepanjang tahun. Dalam setahun tanaman stroberi di Indonesia dapat berproduksi hingga 5 kali tergantung keadaan lingkungan. Berdasarkan ketergantungan terhadap fotoperiodisme dalam pembentukan bunga, tanaman stroberi yang ada di Indonesia tergolong tanaman ever bearing yaitu untuk pembungaan tidak tergantung pada panjang hari dan dapat berbunga sepanjang tahun.

Jumlah bunga yang dihasilkan pada setiap periode menunjukkan perbedaan yang nyata. Secara statistik, bunga yang dihasilkan oleh tanaman dengan perlakuan irigasi manual dua hari sekali lebih sedikit dibandingkan jumlah bunga yang dihasilkan oleh tanaman dengan perlakuan irigasi drip setiap hari, drip dua hari sekali dan irigasi manual setiap hari. Jumlah bunga yang dihasilkan sangat mempengaruhi jumlah buah yang dihasilkan. Jumlah bunga berkorelasi positif terhadap jumlah dan bobot buah panen.

Banyaknya bunga yang gugur tidak dipengaruhi secara nyata oleh perbedaan sistem irigasi. Banyaknya jumlah bunga yang gugur disebabkan oleh suhu yang tinggi yaitu mencapai 28 ${ }^{\circ} \mathrm{C}$ pada periode tertentu dan tingginya curah hujan yang mencapai $451 \mathrm{~mm} /$ bulan selama penelitian. Menurut Schneider dan Scarborough (1960), suhu yang terlalu tinggi selama bunga mekar menyebabkan periode bunga mekar dan reseptivitas stigma menjadi pendek sehingga menghambat pembuahan dan menyebabkan bunga gugur sehingga dapat menurunkan jumlah dan bobot buah panen. Edmond et al. (1957) menyatakan tanaman stroberi mampu beradaptasi dengan baik di dataran tinggi tropis yang memiliki kisaran suhu $17-20{ }^{\circ} \mathrm{C}$. Pada musim hujan banyak bunga yang busuk dan gagal mengalami penyerbukan. Kegagalan penyerbukan dikarenakan air hujan dapat mencuci serbuk sari dari antera dan menghilangkan perekat alami pada stigma.

Produktivitas tanaman ditentukan oleh varietas tanaman, jumlah bunga dan keadaan lingkungan tumbuh. Perbedaan perlakuan irigasi tidak berpengaruh nyata terhadap jumlah buah dan bobot buah panen serta rata-rata bobot buah. Namun demikian, tanaman stroberi yang mendapatkan irigasi setiap hari cenderung menghasilkan buah yang lebih banyak dengan

ukuran buah yang lebih besar. Produktivitas dan ukuran buah terbesar dicapai oleh tanaman dengan perlakuan irigasi menggunakan drip dengan frekuensi setiap hari. Kruger et al. (1999) menyatakan bahwa tanaman stroberi yang mendapatkan irigasi mampu menghasilkan buah yang lebih banyak dengan ukuran yang lebih besar dibandingkan dengan tanaman yang tidak mendapatkan irigasi.

Ukuran buah stroberi ditentukan oleh bunga stroberi. Buah yang dihasilkan oleh bunga primer lebih besar daripada buah yang dihasilkan oleh bunga sekunder dan buah dari bunga sekunder lebih besar daripada buah yang berasal dari bunga tersier. Untuk meningkatkan ukuran buah stroberi, usaha yang telah banyak dilakukan adalah dengan pembuangan bunga tersier dan kuartener, dan mempertahankan bunga primer dan sekunder. Pembuangan bunga tersier dan kuartener bertujuan untuk mengurangi persaingan penggunaan fotosintat antara buah dan bunga, sehingga fotosintat dapat terkonsentrasi untuk perkembangan buah.

Pengkelasan buah stroberi dapat dilakukan berdasarkan ukuran diameter buah atau bobot buah. Pada penelitian ini pengkelasan buah didasarkan pada bobot buah. Pada semua perlakuan, buah kelas A mempunyai persentase berkisar antara 23 sampai $27 \%$. Persentase buah yang busuk tergolong tinggi, yaitu berkisar 20 sampai $27 \%$. Tingginya persentase buah yang busuk diakibatkan oleh hujan yang turun terus menerus sehingga intensitas serangan penyakit meningkat.

Kekerasan buah adalah salah satu faktor penentu kualitas buah. Miner et al. (1997) menyatakan pemberian pupuk yang berlebih dapat mengurangi kekerasan buah stroberi varietas Chandler. Pada keempat perlakuan irigasi yang 
diujikan, buah yang dihasilkan mempunyai nilai kekerasan yang hampir sama. Hal ini menunjukkan bahwa dengan konsentrasi hara dan frekuensi irigasi yang diujikan tidak cukup mempengaruhi nilai kekerasan buah.

Rasa adalah salah satu komponen kualitas yang penting bagi konsumen. Untuk buah stroberi, rasa yang baik adalah manis dengan sedikit asam. Rasa manis dan asam pada stroberi ditentukan oleh rasio PTT/ATT. Kandungan PTT buah menunjukkan kandungan sukrosa yang terkandung dalam sari buah. Moing dan Renaud (2001) menyatakan bahwa selain sukrosa, terdapat dua komponen gula utama lain pada buah stroberi yaitu glukosa dan fruktosa. Kandungan ketiga gula utama ini meningkat seiring dengan fase perkembangan buah. Menurut Wang dan Champ (2000), kandungan PTT buah dipengaruhi oleh kultivar dan lingkungan tumbuh seperti suhu, cahaya, ketersediaan air dan nutrisi tanaman. Pada tomat, pemberian unsur $\mathrm{K}$ dapat meningkatkan ATT dan menurunkan PTT (Pantastico, 1986). ATT adalah banyaknya asam pada buah yang dapat dititrasi sebagai asam sitrat, malat atau tatrat tergantung pada jenis asam organik dominan yang terkandung pada buah (Kader, 1992). Lebih lanjut Wang dan Camp (2000) menyatakan asam sitrat adalah asam yang paling dominan pada buah stroberi. Dalam perlakuan yang diujikan, walaupun tanaman memperoleh nutrisi yang berbeda namun perbedaan tersebut tidak mempengaruhi PTT dan ATT pada buah. Dari nilai PTT dan ATT buah yang tidak berbeda, menunjukkan rasa dari buah stroberi pada keempat perlakuan irigasi tidak berbeda.

\section{KESIMPULAN}

Perbedaan perlakuan irigasi berpengaruh terhadap peubah vegetatif tinggi tanaman dan jumlah nmner tetapi tidak berpengaruh nyata terhadap jumlah daun. Tanaman yang mendapatkan irigasi setiap hari, baik menggunakan drip maupun secara manual mempunyai keragaan yang lebih baik dan menghasilkan rumner lebih banyak dibandingkan dengan tanaman yang mendapatkan irigasi dua hari sekali.

Perlakuan irigasi meningkatkan jumlah bunga yang dihasilkan. Tanaman yang mendapat perlakuan irigasi drip setiap hari cenderung menghasilkan buah dan berproduksi lebih banyak daripada perlakuan yang lain, yaitu mencapai $85.11 \mathrm{~g}$ per tanaman dengan bobot buah rata-rata $13.09 \mathrm{~g}$. Perlakuan irigasi tidak berpengaruh nyata pada komponen kualitas buah, yaitu padatan terlarut total, total asam tertitrasi dan kekerasan buah.

\section{DAFTAR PUSTAKA}

Childers, N. F. 1973. Modern Fruit Science. $5^{\text {th }}$ ed. Somerset Press, Inc. New Jersey. 800 p.

Choopong, S., E.W.M. Veirheij. 1997. Fragaria $x$ ananassa. hal 146-148. In E.W.M. Veirheij dan R.E. Coronel (eds.). Sumberdaya Nabati Asia Tenggara 2: Buah-buahan yang Dapat Dimakan. PT Gramedia Pustaka Utama. Jakarta.

Edmond, J. B., A.M. Musser, F.S. Andrews. 1957. Fundamentals of Horticulture. 2nd ed. McGraw-Hill Book Co. Inc. New York. 500 p.

Gunawan, L.W. 1996. Stroberi. Penebar Swadaya. Jakarta.

Hansen, V.E., O.W. Israelsen, G.E. Stringham. 1980. Irrigation Principles and Practices. John Willey and Sons, Inc. New York. 417 p.

Kader, A.A. 1992. Postharvest biology and technology : An Overview. p. 15-20. In A.A. Kader (ed.). Postharvest Biology and Technology of Horticultural Crops. Univ. California. California. 192 p.

Kruger, E., G. Schmidt, U. Bruckner. 1999. Scheduling strawberry irrigation based upon tensiometer measurement and a climatic water balance model. Scientia Horticulturae. 81:409424.

Miner, G.S., E.B. Poling, D.E. Carol, L.A. Nelson. 1997. Influence of fall nitrogen and spring nitrogen-potassium applications on yield and fruit quality of 'Chandler' strawberry. J. Amer. Soc. Hort. Sci. 122(20):290-295.

Moing, A., C. Renaud. 2001. Biochemical changes during fruit development of four strawberry cultivars. J. Amer. Hort. Sci.126 (4):394-403.

Noviyanti, E., S. Susanto. 2005. Pertumbuhan dan kualitas buah stroberi yang ditanam secara hidroponik pada lingkungan yang berbeda. Gakuryoku 11 (2):195-199. 
Pantastico, E.B. 1986. Faktor-faktor pra panen yang mempengaruhi mutu dan fisiologi pasca panen. hal 39-64. In E.B. Pantastico (eds.). Fisiologi Pasca Panen, Penanganan dan Pemanfaatan Buah-buahan dan Sayur-sayuran Tropika dan Sub Tropika. Gadjah Mada University Press. Yogyakarta.

Prawiranata, W., S. Harran, P. Tjondronegoro. 1995. Dasar-dasar Fisiologi Tumbuhan Jilid 2. FMIPA, IPB. Bogor. 341 hal.

Robert, F., G. Risser, G. Petel. 1999. Photoperiod and temperature effect on growth of strawberry plant (Fragaria ananassa Duch.): development of a morphological test to asses the dormancy induction. Scientia Horticulturae. 82:217-226.

Save, R.S., J. Penuelas, O. Marva, L. Serrano. 1993. Changes in leaf osmotic and elastic properties and canopy structure of strawberries under mild water stress. Hort. Sci. 28:925-927.
Schneider, G.W., C.C. Scarborough. 1960. Fruit Growing. Prentice-Hall, Inc. USA.

Schwarz, M. 1995. Soilless Culture Management. Springer-Verlag, Berlin. $77 \mathrm{p}$.

Shamaila, M., T.E. Baumann. G.W. Eaton, W.D. Powrie, B.J. Skura. 1992. Quality attributes of strawberry cultivars grown in British Columbia. J. Food Sci. 57(3):696-699.

Shoemaker, J.S, 1982. Small Fruit Culture $5^{\text {th }} \mathrm{ed}$. The Avi Publishing Company. Inc. Connecticut.

Wang, S.Y., M.J. Camp. 2000. Temperature after bloom affect plant growth and fruit quality of strawberry. Scientia Horticulturae. 85:183-199.

Warintek-Menteri Negara Riset dan Teknologi. 2004.Stroberi.http://www.ipteknet.id/ind/warin tek/budidaya pert_indx. download $11 \mathrm{Mei}$ 2007. 